\title{
In vivo effect of diallyl sulfide and cimetidine on phenacetin metabolism and bioavailability in rat ${ }^{\star}$
}

\author{
Mirosław M. Szutowski ${ }^{\bowtie}$, Katarzyna Zalewska, Marta Jadczak and Monika Marek \\ Department of Toxicology, The Medical University of Warsaw, Warszawa, Poland
}

Received: 10 September, 2001; revised: 7 February, 2002; accepted: 2 March, 2002

Key words: phenacetin, diallyl sulfide, cimetidine

\begin{abstract}
Numerous cytochrome P450 inhibitors have been described as effective modulators of cytochrome $\mathbf{P 4 5 0}$ isoforms activity in vitro. Their inhibitory efficiency may be considerably modified after in vivo application. The aim of this study was to examine the effect of oral administration of diallyl sulfide - a cytochrome P450 $2 \mathrm{E} 1$ inhibitor and cimetidine - a cytochrome $\mathrm{P} 4502 \mathrm{C} 6$ and $2 \mathrm{C} 11$ inhibitor on rat serum concentration of phenacetin and its metabolite acetaminophen. Both inhibitors increased area under the curve $\left(\mathrm{AUC}_{0-4 \mathrm{~h}}\right.$ ) for phenacetin by $50 \%$. Only cimetidine reduced $\mathrm{AUC}_{0-4 \mathrm{~h}}$ for acetaminophen indicating inhibition of O-deethylation activity. Quinidine - a cytochrome P450 2D subfamily and P-glycoprotein inhibitor did not change significantly phenacetin bioavailability. These results suggest that diallyl sulfide inhibits the deacetylation pathway catalysed by arylamine $N$-acetyl transferase. Beside cytochrome $\mathrm{P} 4501 \mathrm{~A} 2$ other cytochrome $\mathrm{P} 450$ isoforms (2A6 and/or 2C11) are involved in phenacetin O-deethylation in rat.
\end{abstract}

The initial step of phenacetin biotransformation involves O-deethylation to $N$-acetyl$p$-aminophenol, N-deacetylation to $p$-phenetidin and 2-hydroxylation to 2-hydroxyphenacetin (Fig. 1). In rats receiving phenacetin (125 mg/kg b.w.) $63 \%$ of the dose was excreted as $N$-acetyl-p-aminophenol in the free or conjugated form, while $21 \%$ of the dose underwent
N-deacetylation [1]. Phenacetin O-deethylation has been widely used as an index for CYP $1 \mathrm{~A} 2$ activity in human [2-4] and in rat [5-7]. In human liver microsomes CYP 1A2 isoform is the only high affinity $\left(K_{\mathrm{m}}=31 \mu \mathrm{M}\right)$ component capable of phenacetin O-deethylation. However, at higher phenacetin concentrations other CYP isoforms (CYPs: 2A6, 2C9,

\footnotetext{
${ }^{\star}$ Presented at the 8th International Symposium on Molecular Aspects of Chemotherapy, September, 2001, Gdańsk, Poland.

${ }^{凶}$ Address for correspondence: Mirosław M. Szutowski, Katedra i Zakład Toksykologii, Akademia Medyczna w Warszawie, S. Banacha 1, 02-097 Warszawa, Poland; tel/fax: (48 22) 572 0760; e-mail: mszutow@farm.amwaw.edu.pl

Abbreviations: CYP, cytochrome P450; DAS, diallyl sulfide; AUC, area under the curve; P-gp, P-glycoprotein.
} 
2C19, 2D6, 2E1) are involved in phenacetin O-deethylation [3]. In rat liver microsomes the high affinity CYP 1A2 and low affinity CYP $2 \mathrm{E} 1$ isoforms catalyse the O-deethylation pathway [5].
UDP-glucuronyl transferase [17, 18]. Studies in primary cultures of rat hepatocytes revealed that the induction of CYP $2 \mathrm{~B} 1 / 2$ in rat liver may be mediated by its metabolite diallyl sulfone $\left(\mathrm{DASO}_{2}\right)$ [19]. The chemopreventive
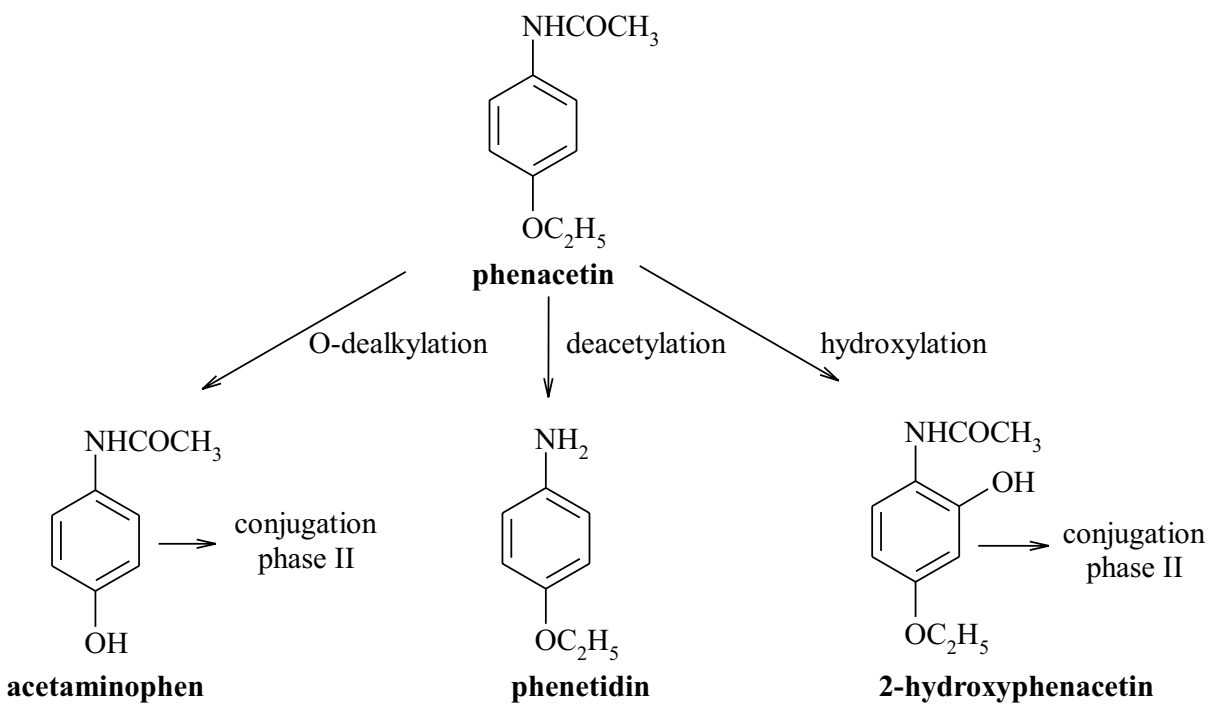

Figure 1. Biotransformation of phenacetin.

Diallyl sulfide (DAS) is a unique CYP inhibitor exhibiting chemoprotective activity. It inhibits induction of colon [8, 9] and liver [10] cancer by 1,2-dimethylhydrazine, as well as esophageal cancer by $N$-nitrosomethylbenzylamine [11], and skin tumour development in mice [12]. DAS inhibits also the activity of CYP 2E1 by competitive inhibition and by decreasing the microsomal level of CYP 2E1 [13]. Besides, it reduces the hepatotoxicity due to exposure to CYP 2E1 substrates acetaminophen, $\mathrm{N}$-dimethylnitrosoamine, and carbon tetrachloride [14, 15].

Further investigations have shown that DAS is a structurally atypical phenobarbital type inducer that induces a number of drug metabolising enzymes of the CYP $2 \mathrm{~B}$ and CYP $3 \mathrm{~A}$ subfamilies, epoxide hydrolase, and, unlike phenobarbital, quinone oxidoreductase. These enzymes catalyse phase I biotransformation reactions (oxidation, reduction, and hydrolysis). DAS coordinately induces phase II conjugating enzymes of the glutathione $S$-transferase $\alpha$ subfamily, glutathione $S$-transferase $\mu$ subfamily [16] and activity of DAS is a result of a variety of biological mechanisms including specific inhibition of some CYP isoforms [20] and induction of phase I and phase II drug metabolising enzymes.

The inhibitory profile of cimetidine on rat liver CYP isoforms is well known from in vitro and in vivo studies [21-23]. Cimetidine inhibits the activity of male-specific non-inducible CYP 2C11 and phenobarbital-inducible CYP 2C6. Another CYP inhibitor quinidine is CYP $2 \mathrm{D}$ subfamily-specific. In addition, it possesses inhibitory activity against intestinal intralumen drug secretion mediated by P-glycoprotein (P-gp) [24]. Substrates of P-gp, including verapamil, diltiazem and digitoxin, inhibit the secretion of quinidine, indicating that it is also a substrate for P-gp [25]. $\mathrm{H}_{2}$ receptor antagonists, cimetidine and ranitidine, were shown to be the substrates for intestinal P-gp and interfered with other substrates, verapamil and cyclosporin [26].

In the present study we investigated the in vivo significance of phenacetin O-deethylation by the CYP 2E1 isoform and the effect of CYP 
inhibitors, diallyl sulfide and cimetidine, on phenacetin bioavailability in rat.

\section{MATERIALS AND METHODS}

Chemicals and reagents. Acetonitrile, dichloromethane and methanol were purchased from Lab-Scan, other chemicals from Sigma-Aldrich. All reagents used were of analytical or HPLC grade.

Animals and treatment. Male Wistar rats (initial weight $190 \pm 10 \mathrm{~g}$ ) were housed with alternating $12 \mathrm{~h}$ light/dark cycles. The rats had free access to standard laboratory food and water. Food was withdrawn $18 \mathrm{~h}$ before phenacetin administration. Phenacetin was dissolved in methanol and given intragastrically at appropriate dose with simultaneously administered $1 \mathrm{ml}$ of water. The amount of methanol did not exceed $1.1 \mathrm{ml} / \mathrm{kg}$ b.w. that represented $6.8 \%$ of $\mathrm{DL}_{50}$ and did not show any signs of intoxication. Up to five kinetic measurements were performed in animals at one-week intervals.

The inhibitor treatment schedule is presented in the text. DAS was given intragastrically at a dose of $200 \mathrm{mg} / \mathrm{kg}$ b.w., dissolved in corn oil (200 mg/ml) or in methanol $(200 \mathrm{mg} / \mathrm{ml}$ ) and ingested simultaneously with $1 \mathrm{ml}$ of water. Cimetidine $(150 \mathrm{mg} / \mathrm{kg}$ b.w.) was given intraperitoneally as hydrogen chloride in $0.9 \%$ sodium chloride [21]. Quinidine was given intragastrically at a dose of 15 $\mathrm{mg} / \mathrm{kg}$ b.w. as water solution $(15 \mathrm{mg} / \mathrm{ml})$.

Blood samples of $0.2 \mathrm{ml}$ were collected from the tail $0.5,1,2,3$ and $4 \mathrm{~h}$ after phenacetin ingestion. Two hours after drug ingestion rats received a dose of $1 \mathrm{ml}$ of water. Serum samples after twofold centrifugation were stored at $-20^{\circ} \mathrm{C}$ until analysis.

Extraction procedure. Serum $(20 \mu \mathrm{l})$ was incubated at $37^{\circ} \mathrm{C}$ with $20 \mu \mathrm{l}$ of $\beta$-glucuronidase/sulfatase (from Helix pomatia, type H1, $40000 / 15000$ (U/U)/g, Sigma, 1.4 U of $\beta$-glucuronidase/ $\mu \mathrm{l}$ ). After $24 \mathrm{~h}, 20 \mu \mathrm{l}$ of 8-chlorotheophylline methanol solution (15 $\mu \mathrm{g} / \mathrm{ml})$ as internal standard, $190 \mu \mathrm{l}$ of $0.9 \%$ sodium chloride, $33 \mu \mathrm{l}$ of $1 \mathrm{M} \mathrm{KH}_{2} \mathrm{PO}_{4}$ and 7 $\mu \mathrm{l}$ of water were added to the serum, shaken with $3 \mathrm{ml}$ of dichloromethane for $5 \mathrm{~min}$ and centrifuged for $10 \mathrm{~min}$ at 4500 r.p.m. The organic phase, after freezing for $30 \mathrm{~min}$ in methanol bath at $-20^{\circ} \mathrm{C}$, was separated from ice and evaporated to dryness at $40^{\circ} \mathrm{C}$. The residue was dissolved in $200 \mu \mathrm{l}$ of mobile phase and $20 \mu \mathrm{l}$ was injected onto HPLC column.

Analytical method. The HPLC system consisted of a Shimadzu LC-10AT solvent delivery module, thermostated CT-10A column oven, SPD-10A UV-VIS detector, RF-551 spectrofluorometric detector and $20 \mu \mathrm{l}$ injection loop (Rheodyne model 7125). Data processing was performed with a Chroma computer integrator.

The assay conditions for phenacetin and acetaminophen were as follows: $\mathrm{ABZ}^{+}$Plus column $5 \mu \mathrm{m}, 15 \mathrm{~cm} \times 4.6 \mathrm{~mm}$ i.d. from Supelco; guard column: Nitrile, $5 \mu \mathrm{m}, 100 \AA, 1.0 \mathrm{~cm} \times$ $3.0 \mathrm{~mm}$ i.d., from Regis; mobile phase: acetonitrile/methanol/0.05 $\mathrm{M} \quad \mathrm{KH}_{2} \mathrm{PO}_{4}$ (135:65:800, by vol.); flow rate $1.5 \mathrm{ml} / \mathrm{min}$; temp. $40^{\circ} \mathrm{C}$; detection UV $\lambda=264 \mathrm{~nm}$.

Statistical methods. Differences between means were analysed using within-subjects design ANOVA and post-hoc Newman-Keuls test with the use of Statistica for Windows. For statistical comparison all experimental variants performed on a single animal were included.

\section{RESULTS}

The rat liver isoform CYP $1 \mathrm{~A} 2$ is the only high affinity phenacetin O-deethylase. Increasing the dose of phenacetin, we expected to show continuously increased participation of other CYP isoforms in its metabolism. As DAS inhibits the CYP 2E1 isoform activity, at higher doses it should partially decrease phenacetin biotransformation and increase phenacetin bioavailability. 
[A] AUC for phenacetin

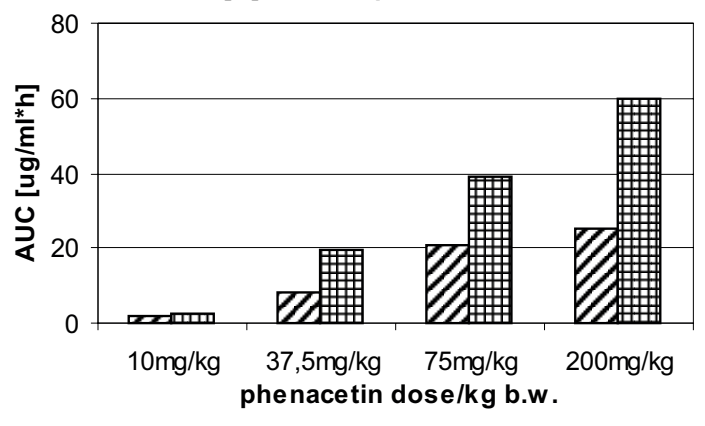

Dhenacetin phenacetin + DAS
[B] AUC for acetaminophen

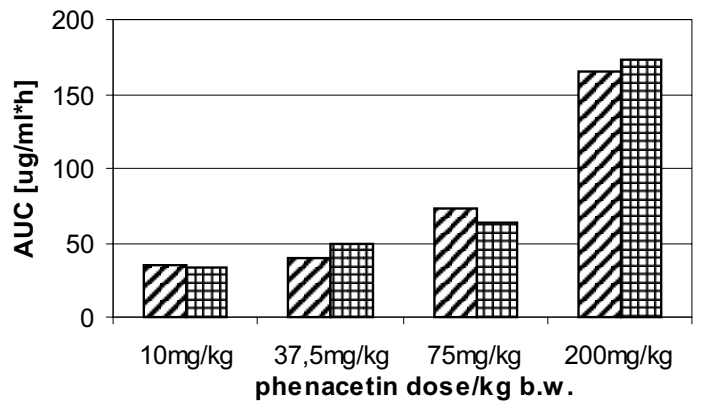

Q7) phenacetin phenacetin + DAS

Figure 2. Effect of diallyl sulfide on $\mathrm{AUC}_{(0-4 \mathrm{~h})}$ of blood serum concentrations of phenacetin (A) and its metabolite acetaminophen $(B)$ at different phenacetin doses.

Each rat received phenacetin at an indicated dose, and one week later, $3 \mathrm{~h}$ before the same dose of phenacetin, rats were given a dose of the inhibitor diallyl sulfide (DAS), $200 \mathrm{mg} / \mathrm{kg}$ b.w. in corn oil.

The results shown in Fig. 2A confirmed that DAS increased 2-fold AUC of blood serum phenacetin concentration at the dose range from 37.5 to $200 \mathrm{mg} / \mathrm{kg}$ b.w. At the same time the AUC of $N$-acetyl-p-aminophenol (Fig. 2B) did not change significantly after DAS pretreatment, indicating unaltered O-deethylation pathway.

Cimetidine was also an effective inhibitor and increased AUC of phenacetin to the com-

[A] AUC for phenacetin and ace tam inophen

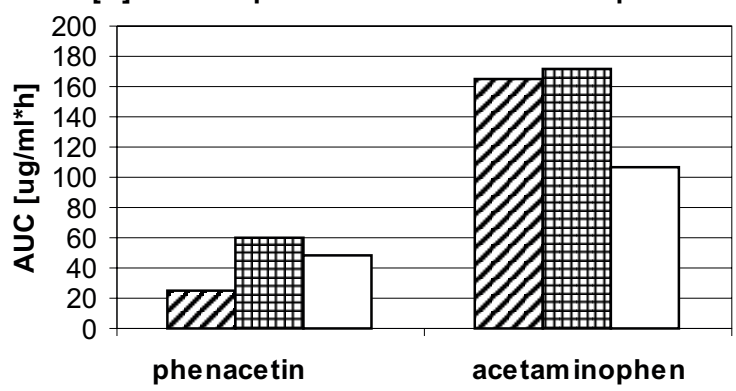

phenacetin phenacetin + DAS

phenacetin + cimetidine parable degree (Fig. 3A). At each time point, metabolite/substrate ratio was calculated and $\mathrm{AUC}_{0.5-4 \mathrm{~h}}$ was estimated (Fig. 3B). Cimetidine inhibited phenacetin O-deethylation activity (Fig. 3A) and the AUC of metabolite/ substrate ratio was decreased after cimetidine pretreatment.

As cimetidine is a substrate for P-gp [26], the next experiment was performed to test if also phenacetin is a substrate for P-gp. The results
[B] AUC for acetaminophen/phe nacetin ratios

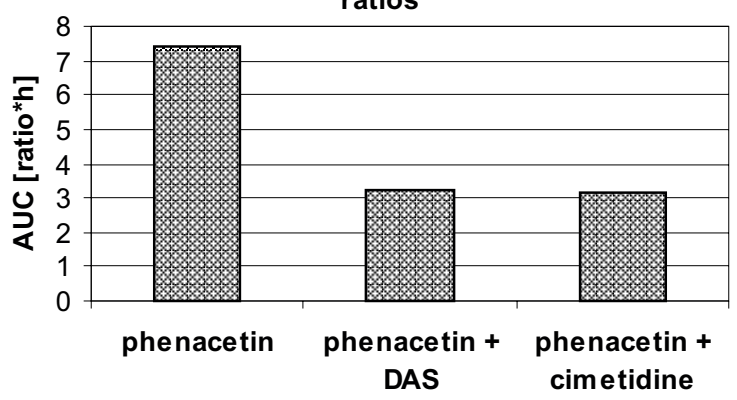

Figure 3. Effect of diallyl sulfide and cimetidine on $\mathrm{AUC}_{(0-4 \mathrm{~h})}$ of blood serum concentrations of phenacetin and acetaminophen (A), and on $\mathrm{AUC}_{(0.5-4 \mathrm{~h})}$ of metabolite/substrate ratios (B).

Each rat received phenacetin at a dose of $75 \mathrm{mg} / \mathrm{kg}$ b.w. and one week later DAS (200 mg/kg b.w.) in corn oil was given, $3 \mathrm{~h}$ before the same dose of phenacetin. Cimetidine $(150 \mathrm{mg} / \mathrm{kg} \mathrm{b}$.w.) was given i.p. $1 \mathrm{~h}$ before the same dose of phenacetin. 
[A] AUC for phenacetin and acetaminophen
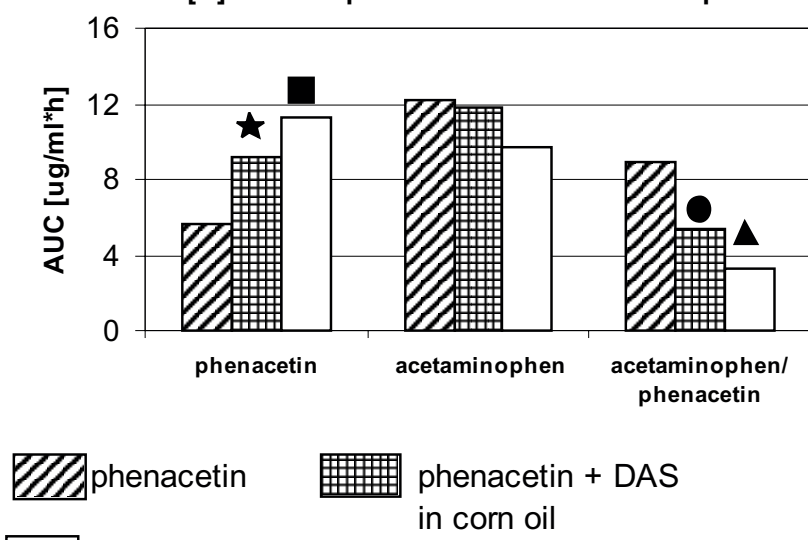

phenacetin + quinidine + DAS in corn oil $\star \mathrm{p}=0.108$

$p=0.101$
[B] AUC for phenacetin and acetam inophen

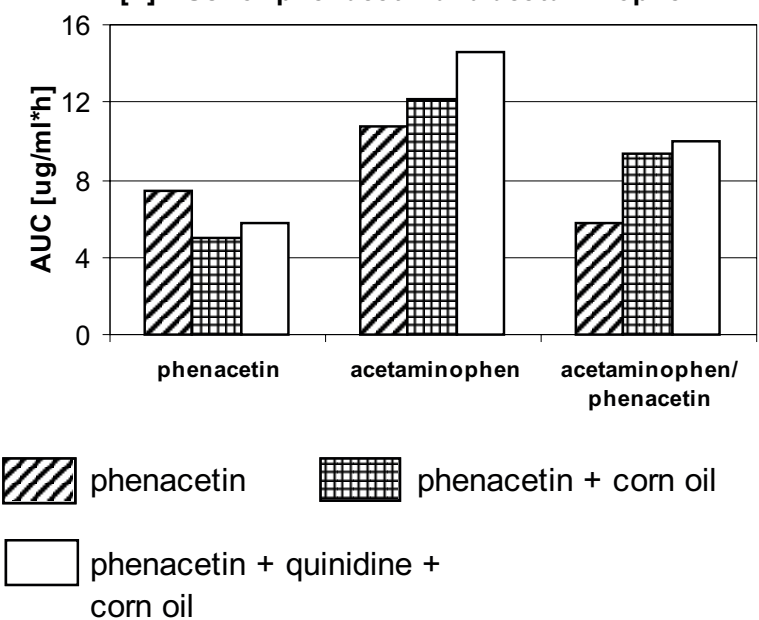

Figure 4. Effect of diallyl sulfide administered in corn oil (vehicle) and quinidine on AUC (0-4 h) of blood serum concentrations of phenacetin and acetaminophen and on $\mathrm{AUC}_{(0.5-4 \mathrm{~h})}$ of metabolite/substrate ratios.

Each rat received phenacetin at a dose of $75 \mathrm{mg} / \mathrm{kg}$ b.w. A. One week later DAS (200 mg/kg b.w.) in corn oil was ingested $3 \mathrm{~h}$ before the same dose of phenacetin. After one more week each rat was given the same dose of DAS $3 \mathrm{~h}$ before, and a dose of quinidine ( $15 \mathrm{mg} / \mathrm{kg} \mathrm{b.w.)} 1 \mathrm{~h}$ before, the same dose of phenacetin. B. One week later each rat was given equivalent volume of corn oil alone, $3 \mathrm{~h}$ before the same dose of phenacetin. After one more week each rat received the same volume of corn oil alone $3 \mathrm{~h}$ before, and a dose of quinidine ( $15 \mathrm{mg} / \mathrm{kg} \mathrm{b} . \mathrm{w}$.) $1 \mathrm{~h}$ before, the same dose of phenacetin.

shown in Fig. 4B do not provide any evidence that quinidine influences phenacetin bioavailability. Corn oil vehicle was used with DAS. When given alone it caused a weak, statistically non-significant decrease of the AUC of phenacetin administered at a dose of $75 \mathrm{mg} / \mathrm{kg}$ b.w. DAS dissolved in corn oil increased the AUC of phenacetin (Fig. 4A).

In order to eliminate the effect of corn oil, DAS was dissolved in methanol. This modification improved the statistical significance of DAS effect on AUC of phenacetin (Fig. 5). The increase in AUC of phenacetin was not accompanied by a decrease in AUC of $N$-acetylp-aminophenol.

\section{DISCUSSION}

An increase in bioavailability of several drugs can be achieved in many ways. Inhibition of P-gp activity and inhibition of enzymes involved in drug biotransformation seem to be the most promising. However, such an approach requires a deep knowledge of the participation of specific enzymes in drug metabolism and the inhibitory spectrum of selected inhibitors.

The presented data indicate that not only CYP 1A2 isoform is involved in phenacetin O-deethylation in rat. Studies with cimetidine suggest an involvement of CYP 2C6 and/or CYP 2C11 in this metabolic pathway. The inhibitory effect of diallyl sulfide on phenacetin biotransformation indicated a negligible role of CYP 2E1 in the O-deethylation activity in rat. Modulation of P-gp activity after ingestion of quinidine did not affect phenacetin bioavailability. An evident increase in the AUC of phenacetin after DAS administration may be expected as a result of $N$-aryl deacetylase inhibition by this inhibitor. About $21 \%$ of the phenacetin dose administered to a rat is converted by $N$-aryl deacetylase to $p$-phenetidine 
[A] AUC for phenacetin and acetaminophen

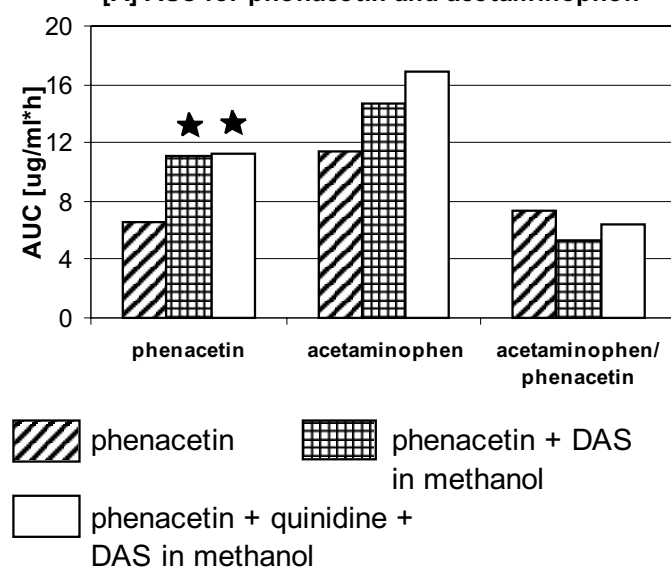

[B] Statis tical significance of AUC differences: $p$-values

\begin{tabular}{lcccc}
\hline & Group 1 & Phen & Phen & Phen+DAS \\
\cline { 2 - 5 } Compared & Group 2 & Phen+DAS & $\begin{array}{c}\text { Phen+DAS+ Phen+DAS+ } \\
\text { Qui }\end{array}$ & Qui \\
\hline AUC for phenacetin & 0.034 & 0.066 & 0.921 \\
\hline \multicolumn{4}{c}{0.121} & 0.382 \\
\hline AUC for acetaminophen & 0.204 & 0.032 & 0.592 \\
\hline $\begin{array}{l}\text { AUC for metabolite/ } \\
\text { substrate ratios }\end{array}$ & 0.564 & 0.632 & \\
\hline
\end{tabular}

Figure 5. Effect of diallyl sulfide (administered as methanol solution) and quinidine on AUC (0-4 h) of blood serum concentrations of phenacetin and acetaminophen and on AUC (0.5-4 h) of metabolite/substrate ratios.

A. Each rat received phenacetin at a dose of $75 \mathrm{mg} / \mathrm{kg}$ b.w. One week later DAS (200 mg/kg b.w.) in methanol was given $3 \mathrm{~h}$ before the same dose of phenacetin. After one more week each rat was given the same dose of DAS in methanol $3 \mathrm{~h}$ before, and a dose of quinidine (15 mg/kg b.w.) $1 \mathrm{~h}$ before, the same dose of phenacetin. B. Statistical significance of AUC differences. p-values were calculated using the ANOVA within-subject design and the post-hoc Newman-Keuls test for $\mathrm{n}=4$ rats.

[1]. There are no data available on the inhibition of $N$-aryl deacetylase by DAS in rat. On the other hand, DAS inhibits $N$-aryl deacetylase in human bladder tumour cells [27] and in human liver microsomes [28]. DAS has been reported to inhibit the activity of arylamine $\mathrm{N}$-acetyltransferase in strains of Helicobacter pylori from peptic ulcer patients [29].

In summary, the presented results suggest that in rat O-deethylation of phenacetin is not CYP 1A2-specific, and may involve other CYP isoforms (CYP 2C6 and/or CYP 2C11). Greater attention should be paid to the inhibitory action of DAS on $N$-aryl deacetylase reaction, a possible route of modification of the bioavailability of drugs.

\section{R E F E R E N C E S}

1. Hansten, P.D. (1985) Drug Interactions. (Lea, \& Febiger, eds.) p. 419, Philadelphia.
2. Tassaneeyakul, W., Birkett, D.J. \& Veronese, M.E. (1993) Specificity of substrate and inhibitor probes for human cytochromes P450 1A1 and 1A2. J. Pharmacol. Exp. Ther. 265, 401-407.

3. Venkatakrishnan, K., von Moltke, L.L. \& Greenblatt, D.J. (1998) Human cytochrome P450 mediating phenacetin O-deethylation in vitro: Validation of the high affinity component as an index of CYP 1A2 activity. $J$. Pharm. Sci. 87, 1502-1507.

4. Yang, T.J., Say, Y., Krausz, K.W., Gonzalez, F.J. \& Gelboin, H.V. (1998) Inhibitory monoclonal antibodies to human cytochrome P450 1A2: Analysis of phenacetin O-deethylation in human liver. Pharmacogenetics 8, 375-382.

5. Kitada, M., Kamataki, T. \& Kitagawa, H. (1978) Enhancement in vivo of drug oxidation following administration of benzphetamine, acetone, metyrapon and dimetylosulfoxide. Jpn. J. Pharmacol. 28, 213-221. 
6. Sesardic, D., Edwards, R.J., Davies, D.S., Thomas, P.E., Levin, W. \& Boobis, A.R. (1990) High affinity phenacetin $O$-deethylase is catalysed specifically by cytochrome P450 1A2 in the liver of the rat. Biochem. Pharmacol. 39, 489-498.

7. Shimada, T., Mimura, M., Inoue, K., Nakamura, S., Oda, H., Ohmari, S. \& Yamazaki, H. (1997) Cytochrome P450-dependent drug oxidation activities in liver microsomes of various animal species including rats, guinea pig, dogs, monkeys and humans. Arch. Toxicol. 71, 401-408.

8. Wargovich, M.J. \& Goldgberg, M.T. (1985) Diallyl sulfide, a naturally occurring thioether that inhibits carcinogen-induced nuclear damage to colon epithelial cells in vivo. Mutat. Res. 143, 127-129.

9. Wargovich, M.J. (1987) Diallyl sulfide, a flavor component of garlic (Allium sativum), inhibits dimethylhydrazine-induced colon cancer. Carcinogenesis 8, 487-489.

10. Hayes, M.A, Rushmore, T.H. \& Goldberg, M.T. (1987) Inhibition of hepatocarcinogenic responses to 1,2-dimethylhydrazine by diallyl sulfide, a component of garlic oil. Carcinogenesis 8, 1155-1157.

11. Wargovich, M.J, Woods, C., Eng, V.W.S., Stephens, L.C. \& Gray, K. (1988) Chemoprevention of $N$-nitrosomethylbenzylamine-induced esophageal cancer in rats by the naturally occurring thioether, diallyl sulfide. Cancer Res. 48, 6872-6875.

12. Dwivedi, C., Rohlfs, S., Jarvis, D. \& Engineer, F.N. (1992) Chemoprevention of chemically induced skin tumor development by diallyl sulfide and diallyl disulfide. Pharmaceut. Res. 9, $1668-1670$

13. Brady, J.F, Li, D., Ishizaki, H. \& Yang, C.S. (1988) Effect of diallyl sulfide on rat liver microsomal nitrosoamine metabolism and other monooxygenase activities. Cancer Res. 48, 5937-5940.
14. Yang, C.S,, Yoo, J.-S., Ishizaki, H. \& Hong, J.-Y. (1990) Cytochrome P450IIE1: Roles in nitrosamine metabolism and mechanisms of regulation. Drug Metab. Rev. 22, 147-160.

15. Brady, J.F, Wang, M.-H., Hong, J.-Y., Xiao, F., Li, Y., Yoo, J.-S.H., Ning, S.M., Lee, M.-J., Fukuto, J.M., Gapac, J.M. \& Yang, C.S. (1991) Modulation of rat hepatic microsomal monooxygenase enzymes and cytotoxicity by diallyl sulfide. Toxicol. Appl. Pharm. 108, 342-354.

16. Dragnev, K.H., Nims, R.W. \& Lubet, R.A. (1995) The chemopreventive agent diallyl sulfide a structurally atypical phenobarbital-type inducer. Biochem. Pharmacol. 50, 2099-2104.

17. Haber, D., Siess, M.H., Canivenc-Lavier, M.C., Le Bon, A.M. \& Suchetet, M. (1995) Differential effects of dietary diallyl sulfide and diallyl disulfide on rat intestinal and hepatic drugmetabolizing enzymes. J. Toxicol. Env. Health 44, 423-434.

18. Guyonnet, D., Siess, M.H., Le Bon, A.M. \& Suchetet, M. (1999) Modulation of phase II enzymes by organosulfur compounds from allium vegetables in rat tissues. Toxicol. Appl. Pharm. 154, 50-58.

19. Pan, J., Hong, J.-Y., Li, D., Schuetz, E.G., Guzelian, P.S., Huang, W. \& Yang, C.S. (1993) Regulation of cytochrome P450 2B1/2 genes by diallyl sulfone, disulfiram, and other organosulfur compounds in primary cultures of rat hepatocytes. Biochem. Pharmacol. 45, 2323-2329.

20.Hong, J.Y., Smith, T., Lee, M.-J., Li, W., Ma, B.L., Ning, S.M., Brady, J.F., Thomas, P.E. \& Yang, C.S. (1991) Metabolism of carcinogenic nitrosoamines by rat liver nasal mucosa and the effect of diallyl sulfide. Cancer Res. 51, $1509-1514$

21. Chang, T., Levine, M., Bandiera, S.M. \& Bellward, G.D. (1992) Selective inhibition of rat hepatic microsomal cytochrome P-450. I. Effect of the in vivo administration of cime- 
tidine. J. Pharmacol. Exp. Ther. 260, 14411449 .

22. Chang, T., Levine, M. \& Bellward, G.D. (1992) Selective inhibition of rat hepatic microsomal cytochrome P-450. II. Effect of the in vitro administration of cimetidine. J. Pharmacol. Exp. Ther. 260, 1450-1455.

23.Levine, M., Law, E.Y.W., Bandiera, S.M., Chang, T.K.H. \& Bellward, G.D. (1998) In vivo cimetidine inhibits hepatic CYP2C6 and CYP2C11 but not CYP1A1 in adult male rats. J. Pharmacol. Exp. Ther. 284, 493-499.

24. Su, S.F. \& Huang, J.D. (1996) Inhibition of the intestinal digoxin absorption and exsorption by quinidine. Drug Metab. Dispos. 24, 142147.

25. Emi, Y., Tsunashima, D., Ogawara, K., Higaki, K. \& Kimura, T. (1998) Role of P-glycoprotein as a secretory mechanism in quinidine absorption from rat small intestine. J. Pharm. Sci. 87, 295-299.

26. Collett, A., Higgs, N.B., Sims, E., Rowland, M. \& Warhurst, G. (1999) Modulation of the per- meability of $\mathrm{H} 2$ receptor antagonists cimetidine and ranitidine by P-glycoprotein in rat intestine and the human colonic cell line Caco-2. J. Pharmacol. Exp. Ther. 288, 171178.

27. Chung, J.G. (1999) Effects of garlic components diallyl sulfide and diallyl disulfide on arylamine $\mathrm{N}$-acetyltransferase activity in human bladder tumor cells. Drug Chem. Toxicol. 22, 343-358.

28. Kudo, S., Umehara, K., Hosokawa, M., Miyamoto, G., Chiba, K. \& Satoh, T. (2000) Phenacetin deacetylase activity in human liver microsomes: Distribution, kinetics, and chemical inhibition and stimulation. J. Pharmacol. Exp. Ther. 294, 80-88.

29. Chung, J.G., Chen, G.W., Wu, L.T., Lin, J.G., Yeh, C.C. \& Wang, T.F. (1998) Effects of garlic compounds diallyl sulfide and diallyl disulfide on arylamine $\mathrm{N}$-acetyltransferase activity in strains of Helicobacter pylori from peptic ulcer patients. Am. J. Chinese Med. 26, 353-364. 